\title{
Association of material deprivation with discharge location and length of stay after inpatient stroke rehabilitation in Ontario: a retrospective, population-based cohort study
}

\author{
Shannon L. MacDonald MD MSc, Ruth E. Hall PhD, Chaim M. Bell MD PhD, Shawna Cronin MScOT, \\ Susan B. Jaglal PhD
}

\section{Abstract}

Background: Low socioeconomic status is associated with increased risk of stroke and worse poststroke functional status. The aim of this study was to determine whether socioeconomic status, as measured by material deprivation, is associated with direct discharge to long-term care or length of stay after inpatient stroke rehabilitation.

Methods: We performed a retrospective, population-based cohort study of people admitted to inpatient rehabilitation in Ontario, Canada, after stroke. Community-dwelling adults (aged 19-100 yr) discharged from acute care with a most responsible diagnosis of stroke between Sept. 1, 2012, and Aug. 31, 2017, and subsequently admitted to an inpatient rehabilitation bed were included. We used a multivariable logistic regression model to examine the association between material deprivation quintile (from the Ontario Marginalization Index) and discharge to long-term care, and a multivariable negative binomial regression model to examine the association between material deprivation quintile and rehabilitation length of stay.

Results: A total of 18736 people were included. There was no association between material deprivation and direct discharge to long-term care (most v. least deprived: odds ratio [OR] 1.07, 95\% confidence interval [Cl] 0.89-1.28); however, people living in the most deprived areas had a mean length of stay 1.7 days longer than that of people in the least deprived areas $(p=0.004)$. This difference was not significant after adjustment for other baseline differences (relative change in mean 1.02, 95\% $\mathrm{Cl} 0.99-1.04$ ).

Interpretation: People admitted to inpatient stroke rehabilitation in Ontario had similar discharge destinations and lengths of stay regardless of their socioeconomic status. In future studies, investigators should consider further examining the associations of material deprivation with upstream factors as well as potential mitigation strategies.

troke is a major cause of disability in Canada and around the world. ${ }^{1}$ Although inpatient rehabilitation is essential to recovery and functional improvement after stroke, ${ }^{2,3}$ some patients continue to have substantial impairments at the time of discharge. In Ontario, about $3.5 \%$ of people undergoing inpatient rehabilitation for stroke are discharged directly to long-term care. ${ }^{4}$ Given that long-term care facilities have high occupancy rates ${ }^{5}$ and wait-lists ranging from months to years, ${ }^{6}$ this may result in a prolonged length of stay and a decreased capacity to admit new patients to inpatient rehabilitation. Furthermore, returning home is a common patient-identified goal. ${ }^{7}$

A 2015 literature review that included several international studies showed an association between low socioeconomic status and increased risk of stroke, more severe stroke and worse poststroke functional status. ${ }^{8}$ However, the role of socioeconomic status on discharge destination, particularly to longterm care, after inpatient stroke rehabilitation is unclear. 9 To facilitate a safe discharge home, some patients may require home modifications, the purchase of equipment or private supports to supplement the often limited government-funded home care services. ${ }^{10}$ As a result, one could postulate that socioeconomic status affects choice of discharge destination after inpatient rehabilitation.

There is no agreed-on best measure of socioeconomic status in the stroke literature. ${ }^{8}$ Material deprivation is a measure of socioeconomic status in which people experiencing deprivation are described as those who "lack the types of diet, clothing,

Competing interests: Shannon MacDonald is chair or cochair of Toronto Stroke Network committees, a surveyor for Accreditation Canada's Stroke Distinction program (paid position) and a member of the Heart and Stroke Foundation of Canada Health Systems Quality Committee. No other competing interests were declared.

This article has been peer reviewed.

Correspondence to: Shannon MacDonald, shannon.macdonald@mail.utoronto.ca

CMAJ Open 2022 January 25. DOI:10.9778/cmajo.20200300 
housing, environmental, educational, working and social conditions, activities and facilities which are customary, or at least widely encouraged or approved, in the societies to which they belong." 11 Living in an area of high material deprivation has been shown to be associated with worse health outcomes. ${ }^{12}$

The aim of the present study was to determine whether neighbourhood material deprivation is associated with direct discharge to long-term care after inpatient rehabilitation for stroke, and with increased rehabilitation length of stay.

\section{Methods}

\section{Study design}

This was a retrospective, population-based cohort study of community-dwelling adults (aged 19-100 yr) in Ontario, Canada, who were admitted to inpatient rehabilitation after a stroke.

\section{Participants}

We included Ontario residents who were discharged from an acute care hospital with a most responsible diagnosis of ischemic or hemorrhagic stroke (International Statistical Classification of Diseases and Related Health Problems, Tenth Revision codes I63, I64, I60 and I61) ${ }^{13}$ between Sept. 1, 2012, and Aug. 31, 2017, who were subsequently admitted within 3 days to an inpatient rehabilitation bed with the rehabilitation client group code 1 (stroke). ${ }^{14}$ We restricted the cohort to people who had been living at home before their stroke (with or without supports), and who had an inpatient rehabilitation length of stay greater than 3 days and less than the 99th percentile. People with missing material deprivation data were excluded.

\section{Data sources and cohort selection}

We obtained study data from the multiple data sets at ICES, an independent, nonprofit research institute whose legal status under Ontario's health information privacy law allows it to collect and analyze health care and demographic data, without consent, for health system evaluation and improvement.

We obtained sociodemographic information from the Registered Persons Database and Ontario Marginalization Index database, data on comorbidities and acute care from the Discharge Abstract Database, ${ }^{15}$ and information on rehabilitation (including pre- and poststroke living setting and arrangement) from the National Rehabilitation Reporting System. In Ontario, it is mandatory for facilities to report to the National Rehabilitation Reporting System, and the Canadian Institute for Health Information performs data quality checks. ${ }^{16}$ These data sets were linked by means of unique encoded identifiers and analyzed at ICES.

\section{Exposure and outcomes}

Our primary exposure was material deprivation. Material deprivation is 1 of 4 dimensions of the Ontario Marginalization Index, a validated, derived, ecologic-based index that captures differences in marginalization across Ontario. ${ }^{12,17}$ For our observation period, we used the 2011 and 2016 Ontario Marginalization Index at the dissemination area level, which represents a population of $400-700$ people. ${ }^{17,18}$ The indicators for the material deprivation dimension vary slightly by year but generally include education level and ratio of income from government payments, as well as the proportion of the population who are lone-parent families, unemployed, of lowincome status and living in housing in need of major repair. Geographic units are divided into quintiles, with quintile 1 representing the least marginalized $20 \%$ of areas in Ontario and quintile 5 representing the most marginalized areas. ${ }^{17,18}$

The primary outcome was the proportion of people discharged from rehabilitation to long-term care. We recorded and categorized discharge destination as home without health care services; home with health care services (privately or publicly funded); assisted living (including group home, retirement home and supervised living setting); long-term care (including convalescent care, nursing home and home for the aged); acute care; and other or unknown (boarding house, shelter, public place or unknown). We then reduced the primary outcome - discharge destination - to a binary variable: discharge to long-term care (yes) versus discharge to any other destination (no).

The secondary outcome was inpatient rehabilitation length of stay, defined as inpatient rehabilitation discharge date minus admission date.

\section{Covariates}

Potential covariates included age, sex, rurality of residence (rural community $=$ population $\leq 10000$ [Postal Code Conversion File $\left.{ }^{19}\right]$ ), Charlson Comorbidity Index score of 2 or higher, ${ }^{20,21}$ history of atrial fibrillation, ${ }^{22}$ whether the patient received tissue plasminogen activator (tPA), whether the patient was treated on an acute stroke unit, acute care length of stay, prestroke living arrangement (alone or not alone), whether the rehabilitation program was suspended owing to a change in medical status (service interruption) and whether the patient was readmitted to acute care (discharge from and readmission to an inpatient rehabilitation bed within $30 \mathrm{~d}$ ).

We recorded the Functional Independence Measure (FIM) score at rehabilitation admission, which represented the patient's disability level on admission. The FIM is an 18-item instrument consisting of 13 items in the motor component and 5 items in the cognitive component. Patients receive a score ranging from 1 (total assist) to 7 (complete independence) on each item, for a possible total score of 18-126. The FIM is a commonly used functional assessment measure among rehabilitation professionals. ${ }^{23}$ It has been well validated and has good interrater reliability. ${ }^{23,24}$

\section{Statistical analysis}

We calculated means and standard deviations (SDs) for continuous variables, and frequencies and proportions for categoric variables. We analyzed between-group differences using one-way analysis of variance for continuous variables and the Pearson $\chi^{2}$ test for categoric data. Variables were screened for collinearity, defined as a tolerance of less than 0.25 . We excluded receipt of tPA, as it was highly collinear with stroke type, and readmission to acute care, as it is clinically similar to a service interruption; all other covariates 
were included in the regression models. We used a multivariable logistic regression model to examine the association between material deprivation and discharge to long-term care, and a multivariable negative binomial regression model to examine the association between material deprivation and rehabilitation length of stay. Observations with missing data were deleted from the analyses.

Statistical tests were 2-tailed. A $p$ value of $<0.05$ was considered statistically significant. We performed statistical analyses using SAS Enterprise Guide statistical software, version 7.1 (SAS Institute) in a UNIX (The Open Group) environment.

\section{Ethics approval}

The use of data in this project was authorized under section 45 of Ontario's Personal Health Information Protection Act, which does not require additional review by a research ethics board.

\section{Results}

A total of 18736 people met our inclusion criteria and were included in the analysis. The number of people in each quintile increased as material deprivation increased (least deprived, $n=3068$; most deprived, $n=4582$ ) (Table 1). Compared to people living in the least deprived areas, those in the most deprived areas were younger (age 19-49 yr: $5.9 \%$ v. $7.3 \%$; $p<$ 0.001), had more comorbidities (Charlson Comorbidity Index score $\geq 2: 53.8 \%$ v. $60.5 \%$; $p<0.001)$, had a lower rate of atrial fibrillation ( $15.6 \%$ v. $12.0 \% ; p<0.001)$, were more likely to be living alone before their stroke $(24.0 \%$ v. $34.9 \%$; $p<0.001)$, were less likely to be treated with tPA $(15.8 \% \mathrm{v}$. $13.8 \% ; p=0.01)$ and were less likely to be treated on a stroke unit (49.2\% v. 46.9\%; $p=0.03)$. Admission FIM scores were similar across deprivation quintiles.

\section{Outcomes}

There was no association between material deprivation and direct discharge to long-term care (Table 2). When we examined all possible discharge destinations, there were minimal differences between people living in the most deprived areas and those in the least deprived areas (Table 3 ).

Length of stay increased as material deprivation increased (mean length of stay 31.0 [SD 19.4] d for the least deprived quintile v. 32.7 [SD 21.3] d for the most deprived quintile; $p=$ 0.004). People living in the most deprived areas had a mean length of stay 1.7 days longer than that of people living in the least deprived areas. In the adjusted model, being in the most deprived group was not associated with a statistically significantly longer length of stay compared to the least deprived group (relative change in mean 1.02, 95\% confidence interval 0.99-1.04) (Table 2).

\section{Interpretation}

We found no association between material deprivation and direct discharge to long-term care after inpatient stroke rehabilitation. After adjustment for baseline differences, our results are consistent with an absolute difference of at most
$2 \%$ in the proportion of patients discharged to long-term care between the most deprived quintile and the least deprived quintile. People living in the most deprived areas had a mean length of stay 1.7 days longer than that of people in the least deprived areas. However, after we accounted for baseline factors, length of stay was similar across deprivation quintiles. Given an overall mean length of stay of about 32 days, there was a difference of at most 1 day in length of stay between the least and most deprived groups.

In the acute care setting, studies examining the association between socioeconomic status and discharge destination after stroke have provided mixed results. ${ }^{25-30}$ Notably, studies in the United States have shown that, compared to people of higher socioeconomic status, those of lower socioeconomic status are less frequently discharged to inpatient rehabilitation and more frequently transferred to skilled-nursing facilities. ${ }^{28,31,32}$ Skilled-nursing facilities typically provide fewer hours of therapy per week than inpatient rehabilitation facilities and have less specialized staff, a longer average length of stay $(32 \mathrm{~d} \mathrm{v}$. $15 \mathrm{~d})$ and fewer regulations, which result in lower-cost care. ${ }^{33,34}$ Admission to skilled-nursing facilities does not result in the same degree of patient functional improvements as admission to inpatient rehabilitation hospitals. ${ }^{35}$ In comparison, in a 2013 Canadian study that included 11050 people with ischemic stroke or transient ischemic attack admitted to acute care, Huang and colleagues ${ }^{30}$ found no association between neighbourhood income quintile and rate of discharge to inpatient rehabilitation.

In a universal-type health care system, it is possible that socioeconomic status has minimal impact on final discharge destination. Similar to our study, an Australian study showed no association between the Index of Economic Resources (a measure of income and economic wealth) and discharge destination after inpatient rehabilitation. ${ }^{36}$ In contrast, Nguyen and colleagues,${ }^{37}$ in the US, found that people with Medicare coverage were more likely than those with private health insurance to be discharged to a skilled-nursing facility as opposed to home after inpatient acute care rehabilitation. The need for a further admission to some type of care facility after an inpatient rehabilitation stay was considered a negative outcome.

Although material deprivation was not associated with direct discharge to long-term care in our study, there were subtle differences in final discharge destination across deprivation quintiles. The frequency of discharge to assisted living increased as deprivation quintile decreased (least deprived $6.8 \%$, most deprived 4.9\%). In Canada, assisted-living facilities typically provide services such as meals, housekeeping, laundry and some degree of personal assistance; unlike longterm care, the cost of assisted living is typically paid for by the resident. ${ }^{5}$ However, the difference in the frequency of discharge to assisted living was small, and, although it was statistically significant, there was no clinical difference in the frequency of discharge home (with or without health care services) across quintiles.

Given that the cost of an inpatient rehabilitation bed after stroke in 2012 in Ontario was more than $\$ 600 /$ day, ${ }^{38}$ it is important to understand the key drivers of increased length 


\begin{tabular}{|c|c|c|c|c|c|c|c|}
\hline \multirow[b]{2}{*}{ Characteristic } & \multicolumn{6}{|c|}{ Deprivation quintile; no. (\%) of people* } & \multirow[b]{2}{*}{$\begin{array}{c}p \\
\text { value }\end{array}$} \\
\hline & $\begin{array}{c}1 \text { (least) } \\
n=3068\end{array}$ & $\begin{array}{c}2 \\
n=3411\end{array}$ & $\begin{array}{c}3 \\
n=3723\end{array}$ & $\begin{array}{c}4 \\
n=3952\end{array}$ & $\begin{array}{l}5 \text { (most) } \\
n=4582\end{array}$ & $\begin{array}{c}\text { Total } \\
n=18736\end{array}$ & \\
\hline Age at admission, yr & & & & & & & $<0.001$ \\
\hline $19-49$ & $182(5.9)$ & $193(5.7)$ & $209(5.6)$ & $227(5.7)$ & $333(7.3)$ & $1144(6.1)$ & \\
\hline $50-59$ & $332(10.8)$ & 405 (11.9) & 440 (11.8) & $482(12.2)$ & 767 (16.7) & 2426 (12.9) & \\
\hline $60-69$ & $612(19.9)$ & $692(20.3)$ & $829(22.3)$ & 906 (22.9) & $1060(23.1)$ & 4099 (21.9) & \\
\hline $70-79$ & $830(27.1)$ & $944(27.7)$ & $1002(26.9)$ & $1044(26.4)$ & $1153(25.2)$ & $4973(26.5)$ & \\
\hline $80-89$ & $909(29.6)$ & $987(28.9)$ & $1017(27.3)$ & $1081(27.4)$ & $1040(22.7)$ & $5034(26.9)$ & \\
\hline $90-100$ & $203(6.6)$ & $190(5.6)$ & $226(6.1)$ & $212(5.4)$ & $229(5.0)$ & $1060(5.7)$ & \\
\hline Female sex & $1352(44.1)$ & $1574(46.1)$ & $1730(46.5)$ & $1858(47.0)$ & $2100(45.8)$ & $8614(46.0)$ & 0.2 \\
\hline Stroke type & & & & & & & 0.04 \\
\hline Ischemic & $2637(86.0)$ & $2912(85.4)$ & $3230(86.8)$ & 3449 (87.3) & $4005(87.4)$ & $16233(86.6)$ & \\
\hline Hemorrhagic & $431(14.0)$ & $499(14.6)$ & $493(13.2)$ & $503(12.7)$ & $577(12.6)$ & $2503(13.4)$ & \\
\hline Received tPA $†$ & $417(15.8)$ & $447(15.4)$ & $502(15.5)$ & $461(13.4)$ & $551(13.8)$ & $2378(14.6)$ & 0.01 \\
\hline Treated on acute stroke unit & $1509(49.2)$ & $1627(47.7)$ & $1738(46.7)$ & $1792(45.3)$ & $2148(46.9)$ & $8814(47.0)$ & 0.03 \\
\hline Acute care length of stay, mean $\pm S D, d$ & $12.2 \pm 13.4$ & $12.2 \pm 12.3$ & $11.8 \pm 12.8$ & $12.4 \pm 14.3$ & $12.4 \pm 13.7$ & $12.2 \pm 13.4$ & 0.2 \\
\hline Charlson Comorbidity Index score & & & & & & & $<0.001$ \\
\hline $0-1$ & $1416(46.2)$ & $1512(44.3)$ & $1652(44.4)$ & $1660(42.0)$ & $1810(39.5)$ & $8050(43.0)$ & \\
\hline$\geq 2$ & $1652(53.8)$ & $1899(55.7)$ & $2071(55.6)$ & $2292(58.0)$ & $2772(60.5)$ & $10686(57.0)$ & \\
\hline History of atrial fibrillation & $478(15.6)$ & $499(14.6)$ & $549(14.7)$ & $611(15.5)$ & $550(12.0)$ & $2687(14.3)$ & $<0.001$ \\
\hline Rural residence & $244(8.0)$ & $427(12.5)$ & $585(15.7)$ & $611(15.5)$ & $380(8.3)$ & $2247(12.0)$ & $<0.001$ \\
\hline Living arrangement on admission & & & & & & & $<0.001$ \\
\hline Alone & $735(24.0)$ & $847(24.8)$ & $939(25.2)$ & $1119(28.3)$ & $1601(34.9)$ & $5241(28.0)$ & \\
\hline Not alone & $2333(76.0)$ & $2564(75.2)$ & $2784(74.8)$ & $2833(71.7)$ & $2981(65.1)$ & $13495(72.0)$ & \\
\hline \multicolumn{8}{|l|}{ FIM score on admission, mean \pm SD } \\
\hline Motor component & $47.4 \pm 19.9$ & $46.1 \pm 19.6$ & $46.1 \pm 19.8$ & $46.8 \pm 19.6$ & $47.1 \pm 19.5$ & $46.7 \pm 19.7$ & 0.02 \\
\hline Cognitive component & $24.2 \pm 7.0$ & $24.3 \pm 7.0$ & $24.4 \pm 7.0$ & $24.5 \pm 7.0$ & $24.2 \pm 7.0$ & $24.3 \pm 7.0$ & 0.4 \\
\hline Total & $71.6 \pm 23.2$ & $70.5 \pm 23.0$ & $70.5 \pm 23.2$ & $71.2 \pm 23.1$ & $71.3 \pm 22.8$ & $71.0 \pm 23.1$ & 0.2 \\
\hline Total FIM score on admission & & & & & & & 0.5 \\
\hline$>80$ & $1127(36.7)$ & $1176(34.5)$ & $1327(35.6)$ & $1419(35.9)$ & $1668(36.4)$ & $6717(35.8)$ & \\
\hline $40-80$ & $1640(53.5)$ & $1850(54.2)$ & $1982(53.2)$ & $2133(54.0)$ & $2431(53.1)$ & $10036(53.6)$ & \\
\hline$<40$ & $293(9.6)$ & $368(10.8)$ & $396(10.6)$ & $389(9.8)$ & $465(10.1)$ & $1911(10.2)$ & \\
\hline Missing & $8(0.3)$ & $17(0.5)$ & $18(0.5)$ & $11(0.3)$ & $18(0.4)$ & $72(0.4)$ & \\
\hline$\geq 1$ service interruptions & $184(6.0)$ & $202(5.9)$ & $208(5.6)$ & $215(5.4)$ & $264(5.8)$ & $1073(5.7)$ & 0.8 \\
\hline$\geq 1$ readmissions to acute care & $107(3.5)$ & $128(3.8)$ & $142(3.8)$ & $101(2.6)$ & $156(3.4)$ & $634(3.4)$ & 0.02 \\
\hline
\end{tabular}

of stay. The association of socioeconomic status with length of stay may be influenced by health care funding and insurance for hospital care. A study from Singapore, where rehabilitation is not fully publicly funded, showed that patients in partially subsidized beds had a shorter length of stay than those in beds fully paid for by the patient. ${ }^{39}$ Tan and col- leagues ${ }^{39}$ thought this was at least partially a reflection of the ability of patients and families to pay for the balance. In our study, length of stay increased as deprivation quintile increased. However, this increase was accounted for by other baseline factors (e.g., living alone before the stroke and greater comorbidity). 


\begin{tabular}{|c|c|c|c|c|c|}
\hline \multirow[b]{2}{*}{ Outcome } & \multicolumn{5}{|c|}{ Deprivation quintile; OR $(95 \% \mathrm{Cl})$} \\
\hline & 1 (least) & 2 & 3 & 4 & 5 (most) \\
\hline \multicolumn{6}{|l|}{ Discharge to long-term care } \\
\hline Unadjusted & Ref & $0.90(0.74-1.08)$ & $1.04(0.87-1.23)$ & $1.01(0.85-1.20)$ & $1.10(0.93-1.30)$ \\
\hline Adjusted $^{\star} \dagger \ddagger$ & Ref & $0.86(0.70-1.05)$ & $1.02(0.84-1.23)$ & $1.00(0.83-1.20)$ & $1.07(0.89-1.28)$ \\
\hline \multicolumn{6}{|l|}{ Length of stay } \\
\hline Unadjusted, relative change in mean & Ref & $1.01(0.98-1.04)$ & $1.02(0.99-1.05)$ & $1.03(1.00-1.06)$ & $1.05(1.02-1.08)$ \\
\hline Adjusted, relative change in mean ${ }^{\star} \dagger \S$ & Ref & $0.99(0.96-1.01)$ & $1.00(0.97-1.02)$ & $1.01(0.99-1.04)$ & $1.02(0.99-1.04)$ \\
\hline \multicolumn{6}{|c|}{$\begin{array}{l}\text { Note: } \mathrm{Cl}=\text { confidence interval, } \mathrm{OR}=\text { odds ratio, Ref }=\text { reference. } \\
\text { "Adjusted for sex, acute care length of stay, age, stroke type, treatment on an acute stroke unit, Functional Independence Measure score on admission, Charlson } \\
\text { Comorbidity Index score } 2 \text { or greater, history of atrial fibrillation, rurality, prestroke living arrangement, and } 1 \text { or more service interruptions. } \\
\text { †Seventy-two observations were deleted owing to missing variables. } \\
\text { †C-statistic }=0.826 \text {, which indicates a model with good discrimination. } \\
\text { §Deviance divided by degrees of freedom }=1.04 \text {, which indicates a good fit to the negative binomial model. }\end{array}$} \\
\hline
\end{tabular}

Table 3: Association of material deprivation and discharge destination

\begin{tabular}{|lcccccc|}
\hline & \multicolumn{5}{c|}{ Deprivation quintile; no. (\%) of people } \\
\cline { 2 - 5 } Discharge destination & 1 (least) & 2 & 3 & 4 & 5 (most) & $p$ value \\
\hline Long-term care & $242(7.9)$ & $243(7.1)$ & $303(8.1)$ & $315(8.0)$ & $394(8.6)$ & 0.001 \\
\hline Home with paid health care services & $1454(47.4)$ & $1684(49.4)$ & $1810(48.6)$ & $1933(48.9)$ & $2173(47.4)$ & 0.001 \\
\hline Home without health care services & $917(29.9)$ & $945(27.7)$ & $1011(27.2)$ & $1126(28.5)$ & $1380(30.1)$ & 0.001 \\
\hline Assisted living & $210(6.8)$ & $212(6.2)$ & $236(6.3)$ & $200(5.1)$ & $222(4.9)$ & 0.001 \\
\hline Acute care & $144(4.7)$ & $190(5.6)$ & $214(5.8)$ & $234(5.9)$ & $249(5.4)$ & 0.001 \\
\hline Other/unknown & $101(3.3)$ & $137(4.0)$ & $149(4.0)$ & $144(3.6)$ & $164(3.6)$ & 0.001 \\
\hline
\end{tabular}

\section{Limitations}

Although we used a well-described explanatory variable shown to be associated with worse health outcomes, ${ }^{12}$ the Ontario Marginalization Index, the index has limitations. It is an ecologic, not individual, measure of socioeconomic status and is prone to possible ecologic fallacy; a person's deprivation quintile based on their location of residence may not reflect their individual socioeconomic status..$^{40,41}$ However, the use of dissemination areas in this study decreased the potential for ecologic fallacy. Furthermore, relations described with the use of ecologic measures and individual-level indicators are often consistent. ${ }^{41}$

We do not have reliability data for all of the variables and outcomes used, including discharge destination, nor did we account for clustering or stroke severity, as the ICES databases does not contain stroke severity data. Our study examined people who were admitted to inpatient rehabilitation and was not designed to examine potential associations between material deprivation and acceptance to inpatient rehabilitation from acute care. Finally, given differences in funding of health care systems, the applicability of our findings to other settings, particularly those without universal publicly funded hospital care, is unclear.

\section{Conclusion}

People of low socioeconomic status, as measured by material deprivation, who underwent inpatient rehabilitation after stroke were not at a disadvantage in terms of discharge destination, but they stayed an average 1.7 days longer than people of high socioeconomic status. However, this difference was accounted for by other baseline characteristics. In future studies, investigators should consider further examining the associations of material deprivation with upstream factors as well as potential mitigation strategies.

\section{References}

1. Feigin VL, Norrving B, Mensah GA. Global burden of stroke. Circ Res 2017; 120:439-48.

2. Rønning OM, Guldvog B. Outcome of subacute stroke rehabilitation: a randomized controlled trial. Stroke 1998;29:779-84.

3. Juby LC, Lincoln NB, Berman P. The effect of a stroke rehabilitation unit on functional and psychological outcome: a randomised controlled trial. Cerebrovasc Dis 1996;6:106-10.

4. Hall RE, French E, Khan F, et al. Ontario stroke evaluation report 2016: a focus on stroke rehabilitation. Toronto: ICES; 2016. Available: https://www.ices.on.ca/ flip-publication/Ontario-Stroke-Evaluation-Report-2016/files/assets/common/ downloads/publication.pdf (accessed 2020 Nov. 8).

5. Roblin B, Deber R, Kuluski K, et al. Ontario's retirement homes and long-term care homes: a comparison of care services and funding regimes. Can $\mathcal{F}$ Aging 2019;38:155-67. 
6. Information on long-term care homes. Toronto: Toronto Central LHIN; 2018. Available: http://healthcareathome.ca/torontocentral/en/care/Documents/ Toronto\%20Central\%20LTC\%20Wait\%20List\%20Nov\%202018.pdf (accessed 2018 Dec. 9).

7. Kus S, Muller M, Strobl R, et al. Patient goals in post-acute geriatric rehabilitation - goal attainment is an indicator for improved functioning. 7 Rebabil Med 2011;43:156-61.

8. Marshall IJ, Wang Y, Crichton S, et al. The effects of socioeconomic status on stroke risk and outcomes. Lancet Neurol 2015;14:1206-18.

9. Burton JK, Ferguson EEC, Barugh AJ, et al. Predicting discharge to institutional long-term care after stroke: a systematic review and meta-analysis. $7 \mathrm{Am}$ Geriatr Soc 2018;66:161-9.

10. Yakerson A. Home care in Ontario: perspectives on equity. Int 7 Health Serv 2019;49:260-72.

11. Townsend P. Poverty in the United Kingdom: a survey of household resources and standards of living. Middlesex (UK): Penguin Books; 1979.

12. Matheson FI, Dunn JR, Smith KL, et al. Development of the Canadian Marginalization Index: a new tool for the study of inequality. Can 7 Public Health 2012; 103:S12-6.

13. Hall R, Mondor L, Porter J, et al. Accuracy of administrative data for the coding of acute stroke and TIAs. Can 7 Neurol Sci 2016;43:765-73.

14. National Rehabilitation Reporting System metadata. Ottawa: Canadian Institute for Health Information; 2021. Available: https://www.cihi.ca/en/national -rehabilitation-reporting-system-metadata (accessed 2021 Apr. 15).

15. Juurlink D, Preyra C, Croxford R, et al. Canadian Institute for Health Information Discharge Abstract Database: a validation study. Toronto: Institute for Clinical Evaluative Sciences; 2006.

16. National Rehabilitation Reporting System - data quality documentation, 2019-2020. Ottawa: Canadian Institute for Health Information; 2020.

17. Matheson FI; Ontario Agency for Health Protection and Promotion (Public Health Ontario). 2011 Ontario Marginalization Index: user guide. Toronto: St. Michael's Hospital; 2017. [Joint publication with Public Health Ontario]. Available: https://www.publichealthontario.ca/-/media/documents/O/2017/on -marg-user-2011.pdf?la=en (accessed 2020 Sept. 2).

18. Matheson FI, Moloney G, van Ingen T. 2016 Ontario Marginalization Index: user guide. Toronto: St. Michael's Hospital; 2018. [Joint publication with Public Health Ontario]. Available: https://www.publichealthontario.ca/-/media/ documents/O/2017/on-marg-userguide.pdf?la=en (accessed 2021 Apr. 21).

19. du Plessis V, Beshiri R, Bollman RD, et al. Definitions of "rural." Agriculture and rural working paper series Working Paper no. 61. Ottawa: Statistics Canada; 2002.

20. Hall RE, Porter J, Quan H, et al. Developing an adapted Charlson Comorbidity Index for ischemic stroke outcome studies. BMC Health Serv Res 2019; 19:930.

21. Jiménez Caballero PE, López Espuela F, Portilla Cuenca JC, et al. Charlson Comorbidity Index in ischemic stroke and intracerebral hemorrhage as predictor of mortality and functional outcome after 6 months. 7 Stroke Cerebrovasc Dis 2013;22:e214-8.

22. Tu K, Nieuwlaat R, Cheng SY, et al. Identifying patients with atrial fibrillation in administrative data. Can 7 Cardiol 2016;32:1561-5.

23. Cohen ME, Marino RJ. The tools of disability outcomes research functional status measures. Arch Phys Med Rehabil 2000;81:S21-9.

24. Ottenbacher KJ, Hsu Y, Granger CV, et al. The reliability of the functional independence measure: a quantitative review. Arch Phys Med Rehabil 1996;77:1226-32.

25. Agarwal S, Menon V, Jaber WA. Outcomes after acute ischemic stroke in the United States: Does residential ZIP code matter? 7 Am Heart Assoc 2015;4: e001629.

26. Aslanyan S, Weir CJ, Lees KR, et al. Effect of area-based deprivation on the severity, subtype, and outcome of ischemic stroke. Stroke 2003;34:2623-8.

27. van den Bos GA, Smits JP, Westert GP, et al. Socioeconomic variations in the course of stroke: Unequal health outcomes, equal care? 7 Epidemiol Community Health 2002;56:943-8.

28. Gregory PC, Han E. Disparities in postacute stroke rehabilitation disposition to acute inpatient rehabilitation vs. home: findings from the North Carolina Hospital Discharge Database. Am 7 Phys Med Rehabil 2009;88:100-7.

29. Spieler JF, Lanoe JL, Amarenco P. Socioeconomic aspects of postacute care for patients with brain infarction in France. Cerebrovasc Dis 2002;13:132-41.

30. Huang K, Khan N, Kwan A, et al. Socioeconomic status and care after stroke: results from the Registry of the Canadian Stroke Network. Stroke 2013;44:477-82.

31. Sandel ME, Wang H, Terdiman J, et al. Disparities in stroke rehabilitation: results of a study in an integrated health system in northern California. PMR 2009;1:29-40.

32. Freburger JK, Holmes GM, Ku LJ, et al. Disparities in postacute rehabilitation care for stroke: an analysis of the state inpatient databases. Arch Phys Med Rehabil 2011;92:1220-9.

33. Watanabe TK, Esquenazi A, Flanagan S. The transformation of the rehabilitation paradigm across the continuum of care. PM R 2018;10:S264-71.
34. The post-acute continuum for stroke care. Rosemont (IL): American Academy of Physical Medicine and Rehabilitation; 2017. Available: https://www.aapmr. org/docs/default-source/career-center/aapmr-stroke-brochure-4-28-printhighres. pdf? sfvrsn=0\#: :text=Patients $\% 20$ admitted $\% 20$ to $\% 20 \mathrm{a} \% 20$ SNF, a $\% 20$ SNF\% 20 is $\% 2032.1 \% 20$ days (accessed 2020 Oct. 17).

35. Hong I, Goodwin JS, Reistetter TA, et al. Comparison of functional status improvements among patients with stroke receiving postacute care in inpatient rehabilitation vs skilled nursing facilities. FAMA Netw Open 2019;2:e1916646.

36. Nguyen TA, Page A, Aggarwal A, et al. Social determinants of discharge destination for patients after stroke with low admission FIM instrument scores. Arch Phys Med Rebabil 2007;88:740-4

37. Nguyen VQ, PrvuBettger J, Guerrier T, et al. Factors associated with discharge to home versus discharge to institutional care after inpatient stroke rehabilitation. Arch Phys Med Rehabil 2015;96:1297-303.

38. Meyer M, O'Callaghan C, Kelloway L, et al; Ontario's Stroke Reference Group. The impact of moving to stroke rehabilitation best practices in Ontario. Ontario Stroke Network; 2012. Available: https://www.corhealthontario.ca/ The-impact-of-moving-to-stroke-rehabilitation-best-practices-in-Ontario-OSN -Final-Report-Sept-14-2012.pdf (accessed 2020 Sept. 17).

39. Tan WS, Heng BH, Chua KS, et al. Factors predicting inpatient rehabilitation length of stay of acute stroke patients in Singapore. Arch Phys Med Rebabil 2009;90:1202-7.

40. Grundy E, Holt G. The socioeconomic status of older adults: How should we measure it in studies of health inequalities? 7 Epidemiol Community Health 2001; 55:895-904.

41. Summary measures of socioeconomic inequalities in health. Toronto: Public Health Ontario; 2013. Available: https:/www.publichealthontario.ca/-/media/ documents/S/2013/socioeconomic-inequality-measures.pdf?la=en (accessed 2020 Oct. 18).

Affiliations: Departments of Medicine (MacDonald, Bell) and Physical Therapy (Jaglal), and Institute of Health Policy, Management and Evaluation (MacDonald, Hall, Bell, Cronin, Jaglal), University of Toronto; Sinai Health (MacDonald, Bell); ICES (Hall, Bell, Jaglal), Toronto, Ont.; Institute for Better Health (Hall), Trillium Health Partners, Mississauga, Ont.; Toronto Rehabilitation Institute (Cronin, Jaglal), University Health Network, Toronto, Ont.

Contributors: Shannon MacDonald, Ruth Hall, Chaim Bell and Susan Jaglal contributed to study conception and design, and data interpretation. Shannon MacDonald and Shawna Cronin analyzed the data. Shannon MacDonald drafted the manuscript, and Ruth Hall, Chaim Bell, Shawna Cronin and Susan Jaglal revised it critically for important intellectual content. All of the authors approved the final version to be published and agreed to be accountable for all aspects of the work.

Funding: Shannon MacDonald received funding from the Dr. Eliot A. Phillipson - Sinai Health Department of Medicine Fellowship. Susan Jaglal holds the Toronto Rehabilitation Institute Chair at the University of Toronto.

Content licence: This is an Open Access article distributed in accordance with the terms of the Creative Commons Attribution (CC BY-NC-ND 4.0) licence, which permits use, distribution and reproduction in any medium, provided that the original publication is properly cited, the use is noncommercial (i.e., research or educational use), and no modifications or adaptations are made. See: https://creativecommons.org/licenses/by-nc-nd/4.0/.

Data sharing: The data set from this study is held securely in coded form at ICES. Although data-sharing agreements prohibit ICES from making the data set publicly available, access may be granted to those who meet prespecified criteria for confidential access.

Disclaimer: This study was supported by ICES, which is funded by an annual grant from the Ontario Ministry of Health (MOH). The opinions, results and conclusions reported in this paper are those of the authors and are independent from the funding and data sources. No endorsement by ICES or the Ontario $\mathrm{MOH}$ is intended or should be inferred. Parts of this material are based on data or information compiled and provided by the Canadian Institute for Health Information (CIHI). However, the analyses, conclusions, opinions and statements expressed in the material are those of the authors and not necessarily those of CIHI.

Supplemental information: For reviewer comments and the original submission of this manuscript, please see www.cmajopen.ca/content/10/ 1/E50/suppl/DC1. 